\title{
Comparison of the Usefulness of SPE Cartridges for the Determination of $\beta$-Blockers and $\beta$-Agonists (Basic Drugs) in Environmental Aqueous Samples
}

\author{
Magda Caban, Piotr Stepnowski, Marek Kwiatkowski, Joanna Maszkowska, \\ Marta Wagil, and Jolanta Kumirska \\ Institute for Environmental and Human Health Protection, Faculty of Chemistry, University of Gdansk, Wita Stwosza 63, \\ 80-308 Gdansk, Poland \\ Correspondence should be addressed to Jolanta Kumirska; jolanta.kumirska@ug.edu.pl
}

Received 31 December 2014; Revised 13 March 2015; Accepted 17 March 2015

Academic Editor: Kamlesh Shrivas

Copyright (C) 2015 Magda Caban et al. This is an open access article distributed under the Creative Commons Attribution License, which permits unrestricted use, distribution, and reproduction in any medium, provided the original work is properly cited.

Even though the methodology used for the determination of $\beta$-blockers and $\beta$-agonists in environmental samples is based mainly on solid-phase extraction (SPE) and gas chromatography or liquid chromatography with mass spectrometric detection, the available literature data on the applied SPE procedures is rather sparse. In this paper such comparison is presented. Moreover, the usefulness of the eight SPE cartridges for the determination of five $\beta$-blockers (acebutolol, atenolol, metoprolol, nadolol, and propranolol) and two $\beta$-agonists (salbutamol and terbutaline) in environmental aqueous samples using GC techniques is tested. Among them, three (the trifunction sorbent Strata Screen C, the copolymers LiChrolut EN, and the functionalized copolymer Isolute ENV+) were used for the first time for this purpose. It was confirmed that polystyrene-divinylbenzene- $N$-vinylpyrrolidone copolymers (PS-DVB-VP, Strata-X, and Oasis HLB cartridges) have a better potential than a cation-exchange sorbent for the extraction of the target drugs from environmental water samples. However, it should be stressed out that the direct application of the tested SPE conditions for the analysis of real environmental water samples is not possible, and such parameters, like volume of loading sample, appropriate solvents for washing and elution steps, and so forth, must be optimized again in order to achieve satisfactory recovery values for the target compounds.

\section{Introduction}

The increasing consumption of $\beta$-blockers (for the treatment of various cardiovascular disorders like high blood pressure, ischaemic heart disease, and heart rhythm disturbances) and $\beta$-agonists (antiasthmatic drugs) has caused their presence in the environment to become more noticeable. For example, concentrations of metoprolol, propranolol, and nadolol in wastewater treatment plant effluents vary between 25 and $2800 \mathrm{ng} / \mathrm{L}$; they are found in rivers and streams too (e.g., [1$8]$ ). The analytical methods used for their determination are usually based on liquid or gas chromatography with mass spectrometry detection. They are also used for biomedical analysis in urine and blood (e.g., $[9,10])$. With these techniques reliable identification data can be obtained, which is important especially in antidoping control because, apart from their clinical use and therapeutic value, some of these drugs are doping agents, whose use has been forbidden by the Medical Commission of the International Olympic Committee. It should be added that, because of their similar chemical and structural properties (all of them contain aminoethanol groups), $\beta$-blockers and $\beta$-agonists can be analysed in a single run (e.g., $[4,9])$.

Nowadays, the most common method used for extracting pharmaceuticals is solid-phase extraction [11]. The usual sorbent is chemically bonded silica with $\mathrm{C} 18$ or $\mathrm{C} 8$ groups and polystyrene-divinylbenzene copolymers (PS-DVB). In 1990 considerable progress was made in the extraction of polar compounds by the introduction of more polar groups to PSDVB [12]. These polar groups increase sorbent wettability and provide dipole-dipole and $\mathrm{H}$-bonding interaction sites, thus improving the retention of polar analytes; simultaneous 
extraction of different classes of analytes during one run is therefore feasible [11]. The possibility of introducing polar, nonpolar, or ion exchange groups (or even several of them) has resulted in an increasing number of commercially available SPE cartridges. For this reason one needs to assess the usefulness of novel types of SPE cartridges for extracting polar compounds from complex matrices like biological or environmental samples. The situation with $\beta$-blockers and $\beta$ agonists is similar.

Although many different techniques have been used for the extraction of $\beta$-blockers and $\beta$-agonists from surface water, waste waters, urine, or tissue samples (e.g., [13-15]), the most popular one is still SPE (e.g., [1-10, 16-19]). Originally, silica-based materials were applied for this purpose (e.g., [4]), but they were very soon replaced by polymeric sorbents: Waters SPE cartridges, Oasis MCX (e.g., [2, 5, 8, 16, 18]) and Oasis HLB (e.g., [1, 4, 6, 7]), as well as Strata-X from Phenomenex [19]. These sorbents consist basically of PSDVB, but the MCX has been modified with cation-exchange groups. Sorbents based on molecularly imprinted polymers are highly selective and offer satisfactory recoveries of $\beta$-blockers [17], but their high cost precludes their use in routine analysis. Table 1 shows examples of the extraction of target analytes from different samples (surface water, wastewater, urine, and tissue) using SPE. It should be pointed out that in none of the above-mentioned papers the SPE procedure was optimized and the usefulness of different SPE cartridges was tested.

This work therefore is focused on the comparison of the usefulness of the different SPE cartridges for the isolation of five $\beta$-blockers and two $\beta$-agonists (Table 2 ) from environmental water samples. Among them (Table 3), three new ones, such as the trifunctional sorbent Strata Screen C, the copolymers LiChrolut EN, and the functionalized copolymers Isolute $\mathrm{ENV}+$, have never been used for this purpose.

\section{Materials and Methods}

2.1. Chemicals and Apparatus. Acebutolol (hydrochloride), atenolol, nadolol, metoprolol (tartrate), propranolol (hydrochloride), salbutamol, terbutaline (hemisulfate), 2-methylanthracene (internal standard (IS) used to measure the relative response for each analyte during GC/MS measurements), and the commercial mixture of $99 \%$ N,O-bis(trimethylsilyl)trifluoroacetamide (BSTFA) with $1 \%$ trimethylchlorosilane (TMCS) (hereafter BSTFA + 1\% TMCS) were purchased from Sigma-Aldrich (Steinheim, Germany). Methanol, acetonitrile, and hexane were obtained from Chempur (Piekary Śląskie, Poland). All chemicals were more than 97\% pure, and organic solvents were redistilled.

The stock solutions of each compound $(1000 \mu \mathrm{g} / \mathrm{mL})$ except IS (made up in dichloromethylene) were prepared in methanol and stored at $-18^{\circ} \mathrm{C}$. Two working solutions of standard mixtures containing (1) $10 \mu \mathrm{g} / \mathrm{mL}$ of each target compound and (2) $10 \mu \mathrm{g} / \mathrm{mL}$ of each target compound and IS were prepared in methanol. The first one was used for the spiking procedure of the water samples and the second one was subjected to direct derivatization in order to obtain required data for the absolute recovery calculation.
The dry block heater ((Rotilabo Block-Heater H250) Roth, Karlsruhe, Germany) was supplied by Linegal Chemicals (Warsaw, Poland). The gas chromatograph (GC-2010 Plus) coupled to the mass spectrometer (GCMS-QP 2010 SE) was produced by Shimadzu (Kyoto, Japan).

2.2. Sample Preparation. The working solution of standard mixtures containing $10 \mu \mathrm{g} / \mathrm{mL}$ of each target compound was used to spike $250 \mathrm{~mL}$ tap water sample to the concentration $2.5 \mu \mathrm{g} / \mathrm{L}$. There were twenty-four replicates of this concentration. The nonspiked tap water samples were also prepared in order to correctly assess absolute recoveries.

2.3. Comparison of the Usefulness of SPE Cartridges for the Extraction of $\beta$-Blockers and $\beta$-Agonists from Tap Water Samples. Eight types of SPE cartridge (Table 3 ) and two standard SPE procedures (Table 4) were applied in these experiments. Procedure 2 was applied with the cation-exchange cartridges (Strata-X-C, Oasis MCX, and Strata Screen C), Procedure 1 with the others (Table 4). The natural $\mathrm{pH}$ of tap water samples was in the range 7.0-7.6. In Procedure 2, the $\mathrm{pH}$ was adjusted to the required value by the addition of aq. $\mathrm{HCl}$. Each extraction procedure was repeated three times. Analysis of the nonspiked samples was also performed in order to correctly assess absolute recoveries.

\subsection{Testing the Repeatability of the Extraction of $\beta$-Blockers and $\beta$-Agonists from Environmental Water Samples. Two of the cartridges, Strata-X and Strata-X-C representing a copolymer and mixed-mode ion-exchange sorbent, respec- tively, were tested for their reproducibility. For this purpose the extraction was repeated once a week for a month using tap water samples spiked to the same level. The relative standard deviation of the absolute recovery for each compound was calculated.}

2.5. Derivatization. Derivatization was performed using a previously optimized procedure [20]. Briefly, extracts from SPE were transferred continuously into $1.5 \mathrm{~mL}$ reaction vials and the same amount of internal standard $(10 \mu \mathrm{g} / \mathrm{mL})$ was added to all SPE extracts (to measure the relative response for each analyte). Next, the samples were evaporated to dryness under a gentle stream of nitrogen and $50 \mu \mathrm{L}$ of the silylation reagent (a mixture of BSTFA + 1\% TMCS and ethyl acetate; $1: 1, \mathrm{v} / \mathrm{v})$ was added. The vials were closed and agitated for $1 \mathrm{~min}$ using a vortex system. Derivatization was performed at $60^{\circ} \mathrm{C}$ for $30 \mathrm{~min}$. The derivatives were cooled to room temperature and subjected to GC/MS analysis.

2.6. GC/MS Measurements. All GC/MS separations were performed on a fused-silica capillary column Rtx-5 (30 m, $0.25 \mathrm{~mm}$ I.D., $0.25 \mu \mathrm{m}$ film thickness, Restec) in the following temperature programme: $100^{\circ} \mathrm{C}$ for $1 \mathrm{~min}$, from $100^{\circ} \mathrm{C}$ to $300^{\circ} \mathrm{C}$ at $10^{\circ} \mathrm{C} / \mathrm{min}$, and finally $10 \mathrm{~min}$ at $300^{\circ} \mathrm{C}$ (total time $31 \mathrm{~min})$. The temperature of the injector was $300^{\circ} \mathrm{C}$, the transfer line was heated to $300^{\circ} \mathrm{C}$. Helium was used as the carrier gas at a constant flow rate of $2.0 \mathrm{~mL} / \mathrm{min}$. Injections $(2 \mu \mathrm{L})$ were performed in split/splitless injector mode $(60$ 


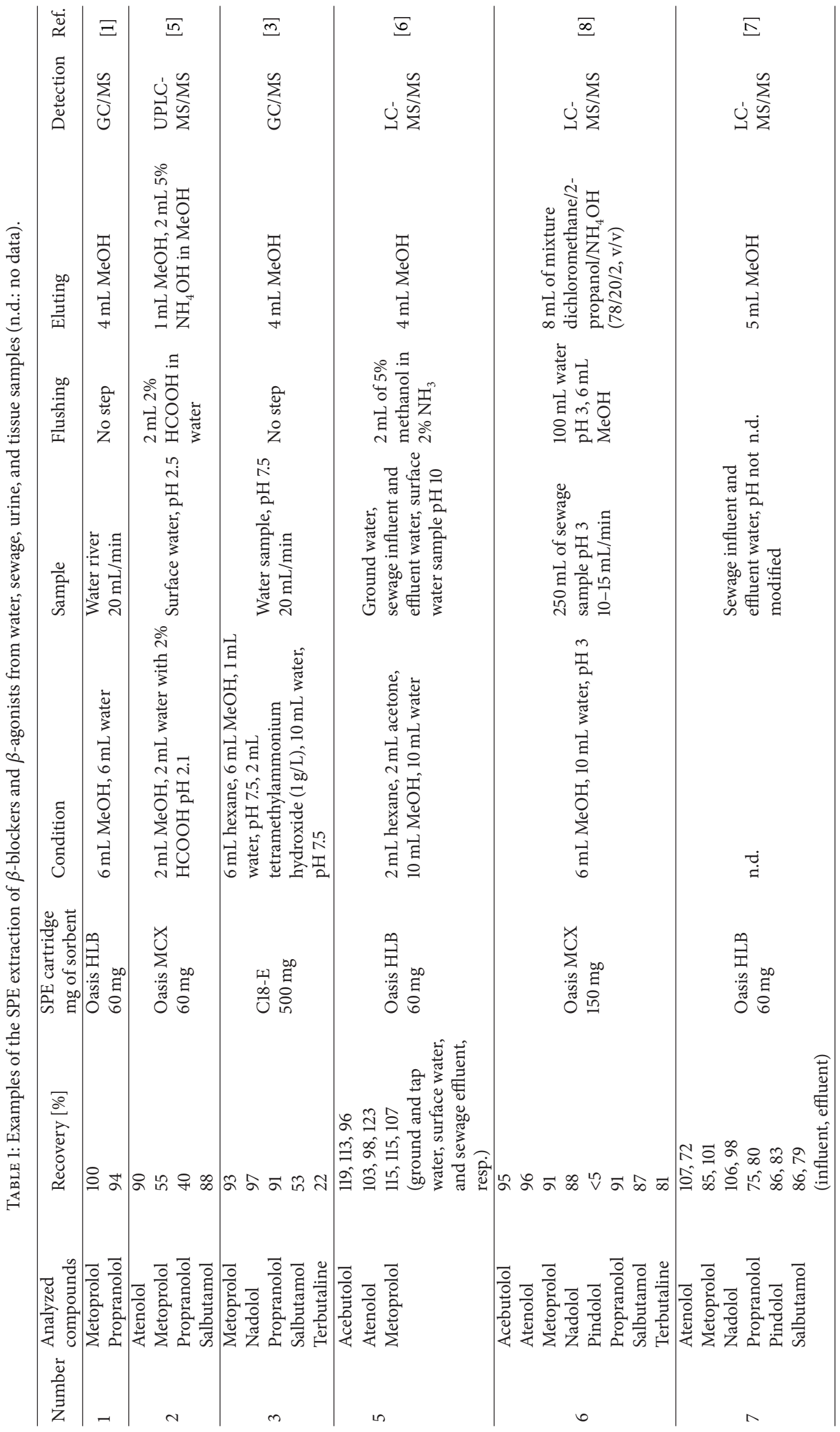




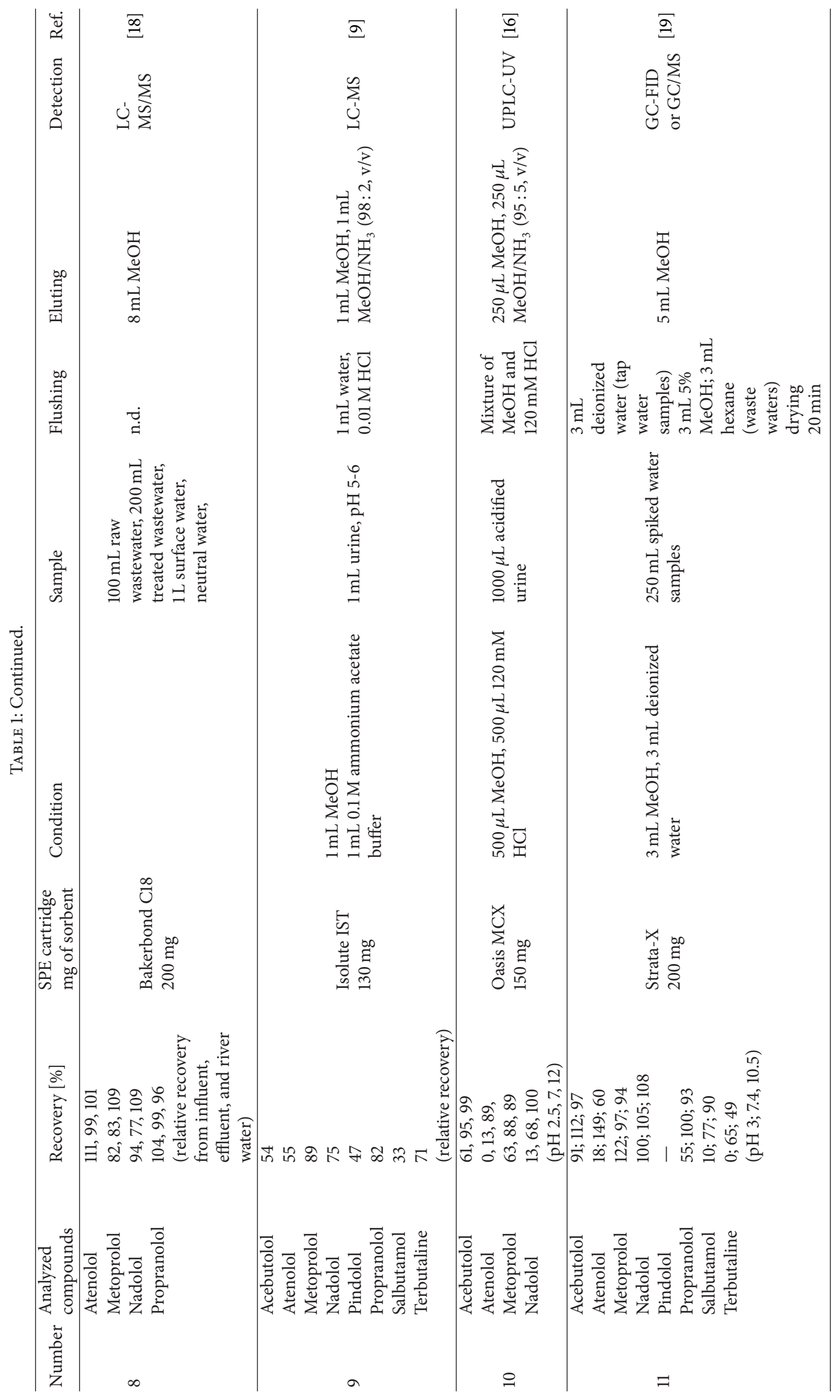


TABLE 2: Chemical structures and properties $\left(\log K_{\mathrm{OW}}, \mathrm{p} K_{\mathrm{a}}\right)$ of the target $\beta$-blockers and $\beta$-agonists.

\begin{tabular}{|c|c|c|c|c|}
\hline Compounds & Molar mass $[\mathrm{g} / \mathrm{mol}]$ & Chemical structure & $\log K_{\mathrm{OW}}$ & $\mathrm{p} K_{\mathrm{a}}$ \\
\hline \multirow[b]{2}{*}{ Acebutolol (ACEB) } & & kers & & \\
\hline & 336.43 & & 1.77 & 9.20 \\
\hline Atenolol (ATEN) & 266.34 & & 0.16 & 9.60 \\
\hline Metoprolol (MET) & 267.36 & & 1.88 & 9.68 \\
\hline Nadolol (NAD) & 309.40 & & 0.71 & 9.67 \\
\hline \multirow[t]{2}{*}{ Propranolol (PROP) } & 259.34 & & -0.45 & 9.45 \\
\hline & & nists & & \\
\hline Salbutamol (SAL) & 239.30 & & 0.64 & $9.2,10.7$ \\
\hline Terbutaline (TERB) & 225.28 & & 0.90 & $8.8,10.1$ \\
\hline
\end{tabular}

seconds splitless, thereafter with a split ratio of 1:5). Mass spectra of the derivatives (EI, $70 \mathrm{eV}$ ) were recorded in selected ion monitoring (SIM) mode. GC peaks were identified by retention times and two characteristic $m / z$ values (MS) [19, 20]. For the quantitative analysis the surface areas of both ions were summed and used to calculate the relative response for each analyte. Each analysis was repeated at least three times.

2.7. Determination of Absolute Recovery of Analytes. The absolute recovery (AR) was calculated using the following equation:

$$
\mathrm{AR}=\left[\frac{\left(\mathrm{RR}_{\text {Pre-Extr }}-\mathrm{RR}_{\text {Non-Spiked }}\right)}{\mathrm{RR}_{\text {Standard }}}\right] \times 100 \%,
$$

where $R R_{\text {Pre-Extr }}$ is the relative response for the analyte recorded for the sample spiked with the target compound prior to extraction, $R R_{\text {Non-Spiked }}$ is the relative response for the analyte recorded for a nonspiked sample, and $R_{\text {Standard }}$ is the relative response for the analyte recorded for the standard solution. AR was calculated according to (1) and given as a mean value.

\section{Results and Discussion}

Eight types of SPE cartridge (Table 3) were used in this study. They could be classified according to the nature of the sorbent.

(i) Silica-based sorbent (Strata C18-E). 
TABLE 3: Chemical structures and characteristic properties of the SPE cartridges.

\begin{tabular}{|c|c|c|c|c|c|}
\hline Number & $\begin{array}{l}\text { SPE column (sorbent } \\
\text { amount/cartridge volume) }\end{array}$ & Chemical structure & Particle and pores size & $\mathrm{pH}$ range & Application \\
\hline 1 & $\begin{array}{l}\text { Isolute } \mathrm{ENV}+ \\
(200 \mathrm{mg} / 6 \mathrm{~mL})\end{array}$ & $\begin{array}{l}\text { Polystyrene-divinylbenzene } \\
\text { copolymer (PS-DVB) diol } \\
\text { modified }\end{array}$ & $\begin{array}{l}90 \mu \mathrm{m} \\
800 \AA\end{array}$ & $1-13$ & $\begin{array}{l}\text { Wide polarity range } \\
\text { analytes }\end{array}$ \\
\hline 2 & $\begin{array}{l}\text { LiChrolut EN } \\
(200 \mathrm{mg} / 3 \mathrm{~mL}) \\
\end{array}$ & PS-DVB & $\begin{array}{l}40-120 \mu \mathrm{m}, \\
30 \AA\end{array}$ & $1-13$ & \\
\hline 3 & Oasis HLB (200 mg/6 mL) & $\begin{array}{l}\text { Polystyrene-divinylbenzene- } N \text { - } \\
\text { vinylpyrrolidone copolymers } \\
\text { (PS-DVB-VP) }\end{array}$ & $\begin{array}{l}30 \text { lub } 60 \mu \mathrm{m} \text {, } \\
80 \AA\end{array}$ & $0-14$ & $\begin{array}{l}\text { Acidic, basic, and } \\
\text { neutral compounds }\end{array}$ \\
\hline 4 & $\begin{array}{l}\text { Strata-X } \\
(200 \mathrm{mg} / 3 \mathrm{~mL})\end{array}$ & (PS-DVB-VP) & $\begin{array}{l}33 \mu \mathrm{m} \\
85 \AA\end{array}$ & $1-14$ & $\begin{array}{l}\text { Acidic, basic, and } \\
\text { neutral compounds } \\
\text { Polar and nonpolar }\end{array}$ \\
\hline 5 & $\begin{array}{l}\text { Strata-X-C } \\
(200 \mathrm{mg} / 3 \mathrm{~mL})\end{array}$ & $\begin{array}{l}\text { PS-DVB modified with sulfonic } \\
\text { (sulfonate) groups }\end{array}$ & $\begin{array}{l}33 \mu \mathrm{m} \\
85 \AA\end{array}$ & $1-14$ & Bases \\
\hline 6 & $\begin{array}{l}\text { Oasis MCX } \\
(150 \mathrm{mg} / 6 \mathrm{~mL})\end{array}$ & $\begin{array}{l}\text { PS-DVB modified with sulfonic } \\
\text { (sulfonate) groups }\end{array}$ & $\begin{array}{l}30 \text { lub } 60 \mu \mathrm{m}, \\
80 \AA\end{array}$ & $0-14$ & Bases \\
\hline 7 & $\begin{array}{l}\text { Strata C18-E } \\
(200 \mathrm{mg} / 6 \mathrm{~mL})\end{array}$ & Octadecyl modified silica & $\begin{array}{l}55 \mu \mathrm{m} \\
70 \AA \\
\end{array}$ & $2-8$ & Nonpolar compounds \\
\hline 8 & $\begin{array}{l}\text { Strata Screen C } \\
(300 \mathrm{mg} / 3 \mathrm{~mL})\end{array}$ & $\begin{array}{l}\text { Octadecyl modified silica with } \\
\text { benzyl-sulfonate groups }\end{array}$ & $\begin{array}{l}55 \mu \mathrm{m} \\
70 \AA\end{array}$ & $2-8$ & $\begin{array}{l}\text { Nonpolar (secondary } \\
\text { nonpolar interactions) } \\
\text { and basic analytes } \\
\text { Basic drugs from } \\
\text { biological samples }\end{array}$ \\
\hline
\end{tabular}

TABLE 4: Standard SPE procedures applied to reversed phases (Procedure 1) and cation-exchange phases (Procedure 2).

\begin{tabular}{lll}
\hline Step & Procedure 1 & Procedure 2 \\
\hline Conditioning & $3 \mathrm{~mL} \mathrm{MeOH}, 3 \mathrm{~mL}$ deionized water & $3 \mathrm{~mL} \mathrm{MeOH}, 3 \mathrm{~mL}$ deionized water pH 3 (adjusted by \\
Sample loading & $\begin{array}{l}250 \mathrm{~mL} \text { water } \\
\text { (not modified) }\end{array}$ & $\begin{array}{l}\text { HCl solution) } \\
\text { (adjusted by } \mathrm{HCl} \text { ) }\end{array}$ \\
Flushing & $3 \mathrm{~mL}$ deionized water & $3 \mathrm{~mL} 5 \%$ formic acid in water, $3 \mathrm{~mL} \mathrm{MeOH}$ \\
Drying & $20 \mathrm{~min}$ & - \\
Eluting & $5 \mathrm{~mL} \mathrm{MeOH}$ & $3 \mathrm{~mL} 5 \%$ ammonium hydroxide in MeOH \\
\hline
\end{tabular}

(ii) Mixed-mode ion-exchange sorbent (Strata-X-C, Oasis MCX).

(iii) Copolymer (LiChrolut EN, Strata-X, and Oasis HLB).

(iv) Functionalized copolymer (Isolute ENV+).

(v) Trifunctional sorbent (Strata Screen C).

As was mentioned, there are three new ones which have never been used for this purpose: the LiChrolut EN cartridge that belongs to the copolymers, the Strata Screen $\mathrm{C}$ that represents trifunctional sorbents, and the Isolute ENV+ that represents the functionalized copolymers. The experiments were performed using the spiked tap water samples and two standard SPE procedures. Procedure 1 is suitable for reversed phases and Procedure 2 is suitable for cationexchange phases (Table 4). We decided to apply the tap water samples (low complex matrices) because we would like to check the ability of the tested cartridges for the sorption of the target compounds (Table 2) during loading step, sorption stability during flushing step, and their desorption potential during elution process in the applied suitable extraction conditions (Table 4) without taking into account the matrix complexity. It is well known that absolute recoveries of the extracted compounds decrease with the increase of the matrix complexity. It means that low ARs parameters obtained in such applied conditions indicate also a low usefulness of these cartridges for the extraction of these compounds from more complex samples (surface waters, waste waters, etc.).

3.1. Comparison of the Effectiveness of $\beta$-Blocker and $\beta$-Agonist Extraction Using Different SPE Cartridges. Comparison of the effectiveness of $\beta$-blocker and $\beta$-agonist extraction using different SPE cartridges was based on absolute recovery values (Table 5).

The Strata Screen C cartridge was tested using two procedures, for reversed-phase sorbents (Procedure 1) and for cation-exchange sorbents (Procedure 2). The results (Table 5) 
TABLE 5: Absolute recoveries (\%) of the target $\beta$-blockers and $\beta$-agonists obtained using nine different extraction procedures (RSD $\leq 10 \%$ ).

\begin{tabular}{|c|c|c|c|c|c|c|c|c|c|}
\hline Compounds & $\begin{array}{c}\text { Isolute } \\
\text { ENV+ } \\
\text { Procedure 1 }\end{array}$ & $\begin{array}{l}\text { LiChrolut } \\
\text { EN } \\
\text { Procedure 1 } \\
\end{array}$ & $\begin{array}{c}\text { Strata-X } \\
\text { Procedure } 1\end{array}$ & $\begin{array}{l}\text { Oasis HLB } \\
\text { Procedure } 1\end{array}$ & $\begin{array}{c}\text { Strata Screen } \\
\text { C } \\
\text { Procedure } 1\end{array}$ & $\begin{array}{c}\text { Strata Screen } \\
\text { C } \\
\text { Procedure } 2 \\
\end{array}$ & $\begin{array}{l}\text { Strata-X-C } \\
\text { Procedure } 2\end{array}$ & $\begin{array}{c}\text { Oasis } \\
\text { MCX } \\
\text { Procedure 2 } \\
\end{array}$ & $\begin{array}{c}\text { Strata } \\
\text { C18-EC } \\
\text { Procedure 1 }\end{array}$ \\
\hline TERB & 92 & 71 & 88 & 101 & 17 & 0 & 82 & 117 & 15 \\
\hline SAL & 93 & 71 & 97 & 91 & 32 & 3 & 71 & 55 & 24 \\
\hline MET & 18 & 25 & 107 & 92 & 71 & 24 & 76 & 122 & 81 \\
\hline PROP & 8 & 16 & 100 & 79 & 71 & 27 & 69 & 119 & 81 \\
\hline ATEN & 78 & 43 & 113 & 115 & 86 & 3 & 125 & 73 & 75 \\
\hline NAD & 73 & 66 & 110 & 106 & 61 & 30 & 67 & 114 & 91 \\
\hline ACEB & 16 & 7 & 63 & 44 & 47 & 0 & 67 & 29 & 20 \\
\hline
\end{tabular}

show that this trifunction sorbent (Table 3) works better as a sorbent for the target compounds when the procedure for reversed phases was applied. However, AR (especially for $\beta$-agonists) with this sorbent is lower than with the other sorbents, for example, the Strata-X cartridge.

In the Strata C18-E cartridge polar interactions (hydrogen bonding) are reduced to a minimum by blocking free hydroxyl groups by end-capping the silica-based surface. ARs for almost all $\beta$-blockers (except acebutolol) are high (Table 5). Unfortunately, the ARs of $\beta$-agonists are low, probably because the van der Waals interactions between these compounds and the sorbent surface were not strong enough.

Isolute ENV+ contains hydroxyl groups on the surface of the PS-DVB skeleton (Table 3 ). As shown in Table 5 , such a modified phase is highly successful for $\beta$-agonist extraction. PS-DVB sorbents contain benzyl groups and $\Pi-\Pi$ bonds between sorbent and all the drugs analysed can easily be formed. Unfortunately, ARs for metoprolol, propranolol, and acebutolol were not good enough (18\%, 8\%, and 16\%, resp.). The structures of terbutaline, salbutamol, and nadolol are similar to those of the sorbent (hydroxyl groups linked to aromatic rings), so these compounds had high ARs.

Strong cation-exchange sorbents (Strata-X-C, Oasis MCX) have good extraction properties with respect to the target analytes (Table 5), and the observed differences are probably due to differences in their manufacture. The Strata$\mathrm{X}-\mathrm{C}$ cartridge seems to have a slightly lower extraction potential for the target compounds, but for three of them (salbutamol, atenolol, and acebutolol) the ARs were better $(71 \%, 125 \%$, and $67 \%$, resp.) in comparison to the MCX cartridge (55\%, 73\%, and $29 \%)$. AR for acebutolol using the Strata-X-C cartridge was the best among all the tested conditions. Scheurer et al. [2] used an Oasis MCX cartridge and very similar conditions for extracting $\beta$-blockers from $1 \mathrm{~L}$ river water. They achieved almost $20 \%$ lower ARs for atenolol, metoprolol, nadolol, and propranolol (58\%, 92\%, $79 \%$, and $66 \%$, resp.) in comparison to the values presented in this work $(73 \%, 122 \%, 114 \%$, and 119\%). Probably during LCMS/MS analysis the matrix effect attenuated analyte signals. On the other hand, Kasprzyk-Hordern et al. [5] reported that the absolute recoveries for atenolol, metoprolol, and propranolol extracted from $1 \mathrm{~L}$ surface water and analysed by LC-MS/MS were 90\%, 55\%, and 49\%, respectively.
Strata-X and Oasis HLB cartridges contain the same sorbent, PS-DVB copolymer modified by $N$-vinylpyrrolidone groups. ARs of the target compounds using the Strata$\mathrm{X}$ column were slightly better for salbutamol, metoprolol, propranolol, and acebutolol in comparison to those obtained with the Oasis HLB cartridge. However both tested cartridges have very good properties for the extraction of the target compound from environmental water samples.

Nonmodified PS-DVB sorbent is present in LiChrolute EN columns (Table 3). Comparison of ARs obtained using this column with those obtained with PS-DVB sorbents modified by polar groups (Strata-X and Oasis HLB) (Table 5) shows how important in the extraction process are bonding forces other than $\Pi-\Pi$, for example, dipole-dipole and induced dipole-dipole bonding. Though weak, these interactions together with $\Pi-\Pi$ bonding enabled good extraction properties for the target compounds to be achieved and were not too strong to continue elution. The ARs of all the compounds were lower using LiChrolute EN, especially the $\beta$-blockers; for example, the value for metoprolol fell from $107 \%$ to $25 \%$ and that for acebutolol fell from $63 \%$ to $7 \%$. On the other hand, Weigel and coworkers [4] reported that ARs for metoprolol and propranolol from tap water ( $\mathrm{pH} 7.4$, elution by methanol) were different (79\% and 65\%, resp.). These large discrepancies can be explained by the fact that two different recovery parameters were used, absolute recoveries in this work and relative recoveries in the cited paper (triclosan was used as internal standard).

To summarize, based on AR parameters (Table 5) among eight tested SPE cartridges, the strong cation-exchange (Strata-X-C, Oasis MCX) and copolymer cartridges (Strata$\mathrm{X}$, Oasis HLB) were found as suitable for extracting the target drugs.

3.2. Repeatability of the Extraction of $\beta$-Blockers and $\beta$ Agonists from Water Samples Using Strong Cation-Exchange and Copolymer Cartridges. The Strata-X-C and Strata-X columns were selected as a representative for these types of copolymers and tested for reproducibility. For this purpose extractions using water samples spiked with drugs to the same level drugs were carried out once a week for a month. The relative standard deviation of AR was calculated for each compound (Figure 1). Using Strata-X cartridges for 


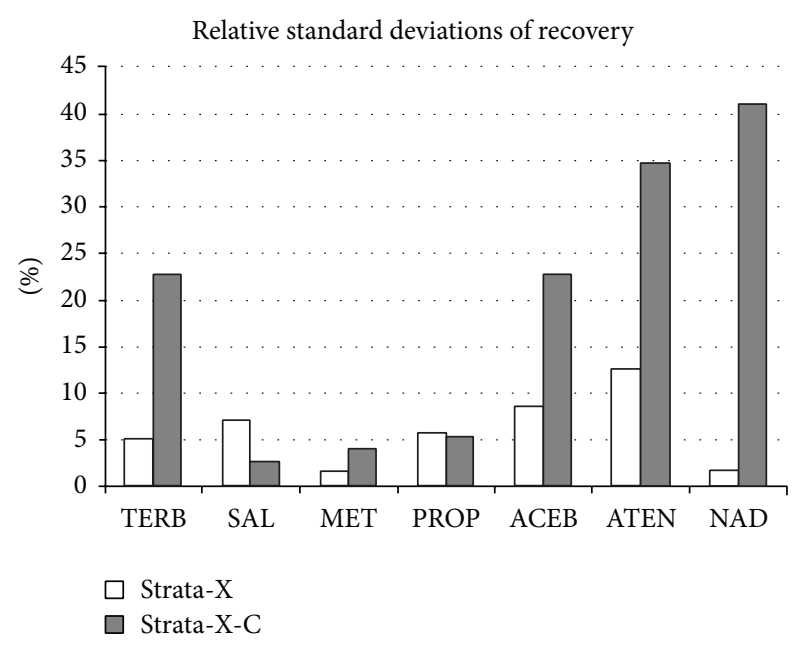

FIGURE 1: RSDs of absolute recoveries obtained for $\beta$-blockers and $\beta$-agonists using Strata-X and Strata-X-C cartridges.

extraction, RSD values did not exceed $12.5 \%$. The application of the Strata-X-C cartridge for extracting $\beta$-blockers and $\beta$-agonists yielded very unstable AR values. RSDs for terbutaline, atenolol, nadolol, and acebutolol were greater than $20 \%$. This indicates that the matrix components have a big impact on the extraction of the target compounds using cation-exchange columns, although the complexity of tap water samples is low. It means that the usefulness of these cartridges for the extraction of the target drugs from more complex matrices such as surface waters or waste waters could be much lower. Thus, the Strata-X and Oasis HLB cartridges were found to be the most suitable cartridges for $\beta$-blocker and $\beta$-agonist extraction from environmental water samples.

\section{Conclusion}

This work summarized the literature data that described the SPE procedures for the extraction of $\beta$-blockers and $\beta$-agonists (basic drugs) from environmental and biological samples. Moreover, the usefulness of the eight SPE cartridges for the isolation of five $\beta$-blockers and two $\beta$-agonists from environmental water samples was tested. Three of them (Strata Screen-C, Isolute ENV+, and LiChrolut EN) were used for the first time. Finally, it was confirmed that polystyrenedivinylbenzene- $N$-vinylpyrrolidone cartridges (PS-DVB-VP, Strata-X, and Oasis HLB cartridges) had better potential than a cation-exchange sorbent for the extraction of basic drugs from environmental water samples. Sorption to the PS-DVB-VP phase was based on dipole-dipole and $\Pi-\Pi$ forces, so the introduction of $N$-vinylpyrrolidone groups to the PS-DVB copolymer significantly increased recovery parameters. However, it should be noticed that the direct application of the applied SPE conditions for the analysis of real environmental water samples is not possible, and typical SPE parameters, like volume of loading sample, appropriate solvents for washing and elution, and so forth, must be tested and optimized again.

\section{Conflict of Interests}

The authors declare that there is no conflict of interests regarding the publication of this paper.

\section{Acknowledgments}

Financial support was provided by the Polish Ministry of Research and Higher Education under Grant DS 530-8610D504-14 and by National Science Centre under Decision DEC-2011/03/B/NZ8/03010 (2012-2015).

\section{References}

[1] C. Miège, M. Favier, C. Brosse, J.-P. Canler, and M. Coquery, "Occurrence of betablockers in effluents of wastewater treatment plants from the Lyon area (France) and risk assessment for the downstream rivers," Talanta, vol. 70, no. 4, pp. 739-744, 2006.

[2] M. Scheurer, M. Ramil, C. D. Metcalfe, S. Groh, and T. A. Ternes, "The challenge of analyzing beta-blocker drugs in sludge and wastewater," Analytical and Bioanalytical Chemistry, vol. 396, no. 2, pp. 845-856, 2010.

[3] T. A. Ternes, R. Hirsch, J. Mueller, and K. Haberer, "Methods for the determination of neutral drugs as well as betablockers and $\beta 2$-sympathomimetics in aqueous matrices using GC/MS and LC/MS/MS," Fresenius' Journal of Analytical Chemistry, vol. 362, no. 3, pp. 329-340, 1998.

[4] S. Weigel, R. Kallenborn, and H. Hühnerfuss, "Simultaneous solid-phase extraction of acidic, neutral and basic pharmaceuticals from aqueous samples at ambient (neutral) $\mathrm{pH}$ and their determination by gas chromatography-mass spectrometry," Journal of Chromatography A, vol. 1023, no. 2, pp. 183-195, 2004.

[5] B. Kasprzyk-Hordern, R. M. Dinsdale, and A. J. Guwy, "Multiresidue methods for the analysis of pharmaceuticals, personal care products and illicit drugs in surface water and wastewater by solid-phase extraction and ultra-performance liquid chromatography-electrospray tandem mass spectrometry," Journal of Chromatography A, vol. 1161, pp. 132-145, 2007.

[6] N. M. Vieno, T. Tuhkanen, and L. Kronberg, "Analysis of neutral and basic pharmaceuticals in sewage treatment plants and in recipient rivers using solid phase extraction and liquid chromatography-tandem mass spectrometry detection," Journal of Chromatography A, vol. 1134, no. 1-2, pp. 101-111, 2006.

[7] S. L. MacLeod, P. Sudhir, and C. S. Wong, "Stereoisomer analysis of wastewater-derived $\beta$-blockers, selective serotonin re-uptake inhibitors, and salbutamol by high-performance liquid chromatography-tandem mass spectrometry," Journal of Chromatography A, vol. 1170, no. 1-2, pp. 23-33, 2007.

[8] H.-B. Lee, K. Sarafin, and T. E. Peart, "Determination of $\beta$ blockers and $\beta 2$-agonists in sewage by solid-phase extraction and liquid chromatography-tandem mass spectrometry," Journal of Chromatography A, vol. 1148, no. 2, pp. 158-167, 2007.

[9] M. Kolmonen, A. Leinonen, A. Pelander, and I. Ojanperä, "A general screening method for doping agents in human urine by solid phase extraction and liquid chromatography/time-offlight mass spectrometry," Analytica Chimica Acta, vol. 585, no. 1, pp. 94-102, 2007.

[10] L. Kristoffersen, E. L. Øiestad, M. S. Opdal, M. Krogh, E. Lundanes, and A. S. Christophersen, "Simultaneous determination of 6 beta-blockers, 3 calcium-channel antagonists, 4 
angiotensin-II antagonists and 1 antiarrhythmic drug in postmortem whole blood by automated solid phase extraction and liquid chromatography mass spectrometry. Method development and robustness testing by experimental design," Journal of Chromatography B, vol. 850, no. 1-2, pp. 147-160, 2007.

[11] C. W. Huck and G. K. Bonn, "Recent developments in polymerbased sorbents for solid-phase extraction," Journal of Chromatography A, vol. 885, no. 1-2, pp. 51-72, 2000.

[12] T. Reemtsma and J. B. Quintana, "Analytical methods for polar pollutants," in Organic Pollutants in the Water Cycle, Wiley$\mathrm{VCH}, \mathrm{GmbH} \& \mathrm{Co}$. KGaA, Weinheim, Germany, 2006.

[13] K. Shrivas and D. K. Patel, "Matrix-assisted laser desorption/ionization mass spectrometry for quantitative determination of $\beta$-blocker drugs in one-drop of human serum sample," Journal of Chromatography B, vol. 879, no. 1, pp. 35-40, 2011.

[14] B. P. Jensen, C. F. Sharp, S. J. Gardiner, and E. J. Begg, "Development and validation of a stereoselective liquid chromatographytandem mass spectrometry assay for quantification of $S$ - and $R$-metoprolol in human plasma," Journal of Chromatography $B$, vol. 865, no. 1-2, pp. 48-54, 2008.

[15] L. Zhang, X. Su, C. Zhang et al., "Extraction and preconcentration of $\beta$-blockers in human urine for analysis with high performance liquid chromatography by means of carrier-mediated liquid phase microextraction," Talanta, vol. 82, no. 3, pp. 984-992, 2010.

[16] I. Marchi, S. Rudaz, and J.-L. Veuthey, "Sample preparation development and matrix effects evaluation for multianalyte determination in urine," Journal of Pharmaceutical and Biomedical Analysis, vol. 49, no. 2, pp. 459-467, 2009.

[17] M. Gros, T.-M. Pizzolato, M. Petrović, M. J. L. de Alda, and D. Barceló, "Trace level determination of $\beta$-blockers in waste waters by highly selective molecularly imprinted polymers extraction followed by liquid chromatography-quadrupolelinear ion trap mass spectrometry," Journal of Chromatography A, vol. 1189, no. 1-2, pp. 374-384, 2008.

[18] A. Piram, A. Salvador, J.-Y. Gauvrit, P. Lanteri, and R. Faure, "Development and optimisation of a single extraction procedure for the LC/MS/MS analysis of two pharmaceutical classes residues in sewage treatment plant," Talanta, vol. 74, no. 5, pp. 1463-1475, 2008.

[19] M. Caban, N. Migowska, P. Stepnowski, M. Kwiatkowski, and J. Kumirska, "Matrix effects and recovery calculations in analyses of pharmaceuticals based on the determination of $\beta$ blockers and $\beta$-agonists in environmental samples," Journal of Chromatography A, vol. 1258, pp. 117-127, 2012.

[20] M. Caban, P. Stepnowski, M. Kwiatkowski, N. Migowska, and J. Kumirska, "Determination of $\beta$-blockers and $\beta$-agonists using gas chromatography and gas chromatography-mass spectrometry-a comparative study of the derivatization step," Journal of Chromatography A, vol. 1218, no. 44, pp. 8110-8122, 2011. 

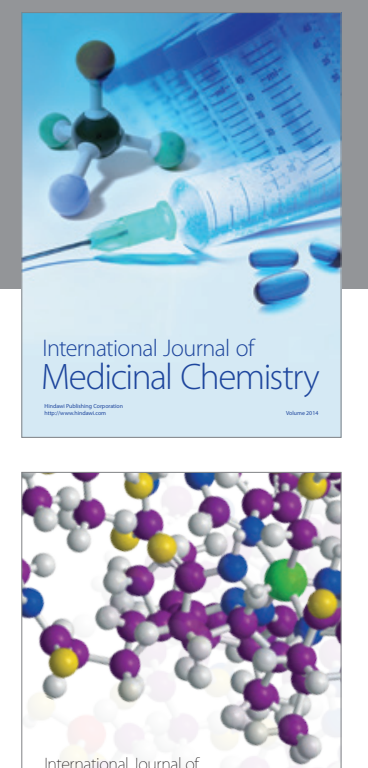

\section{Carbohydrate} Chemistry

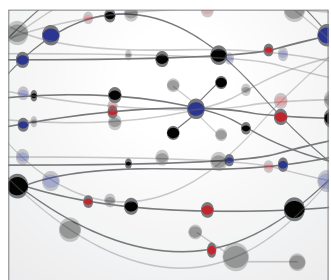

The Scientific World Journal
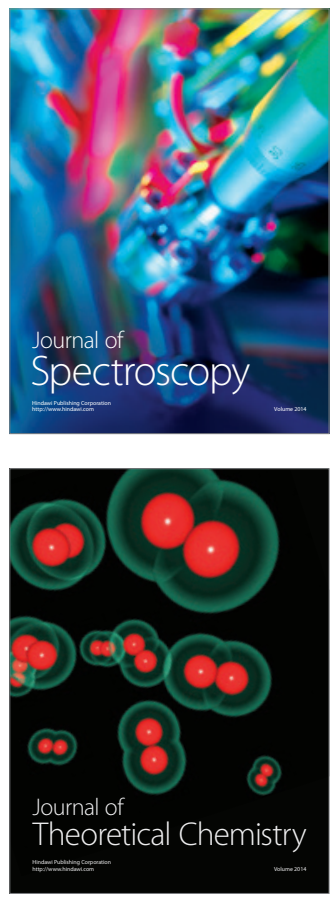
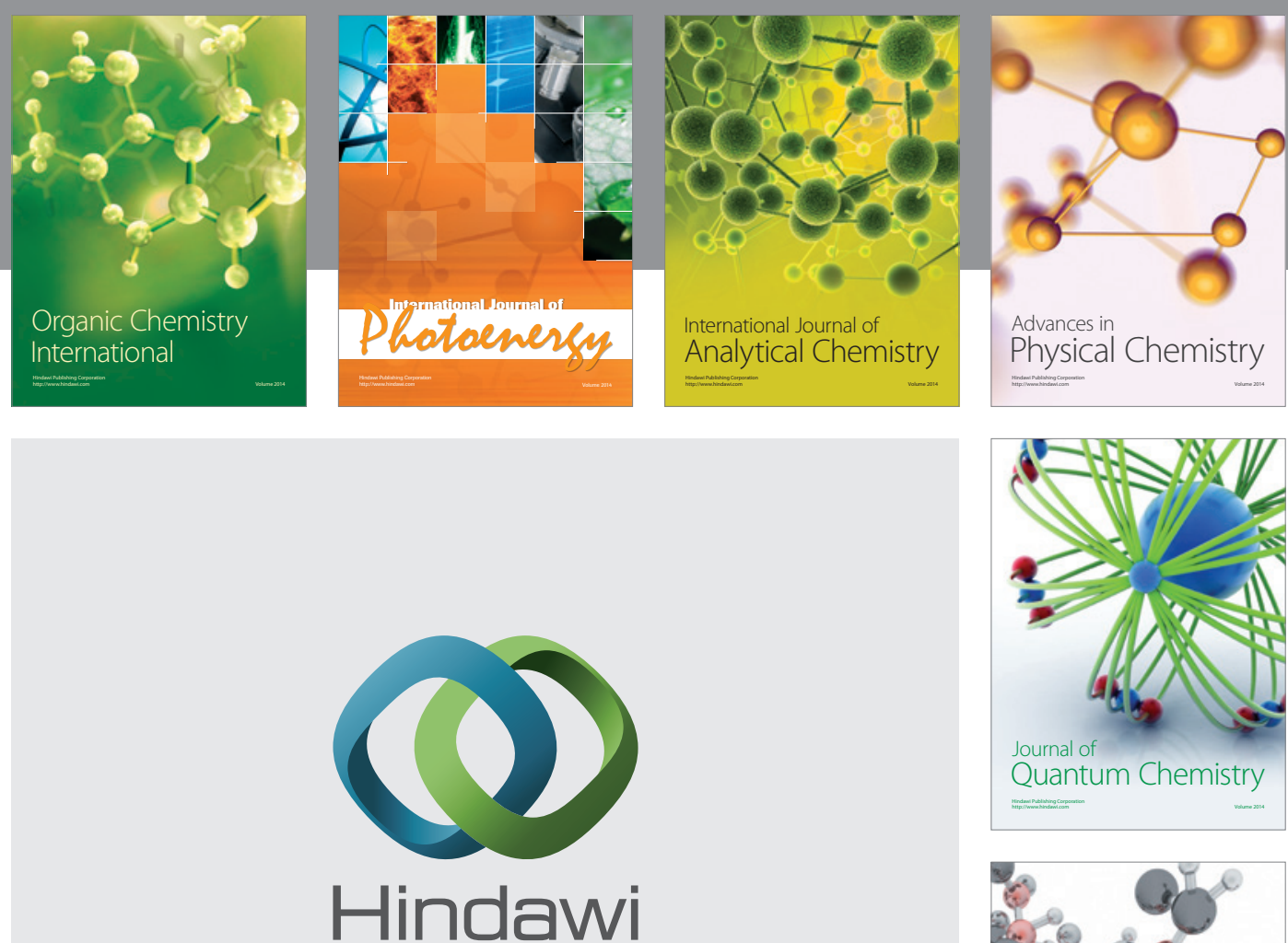

Submit your manuscripts at

http://www.hindawi.com

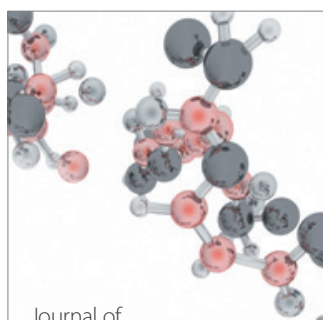

Analytical Methods

in Chemistry

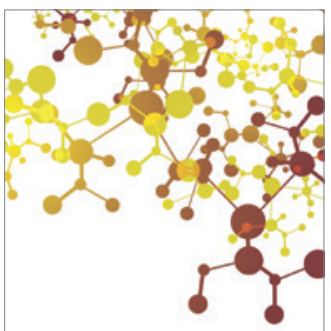

Journal of

Applied Chemistry

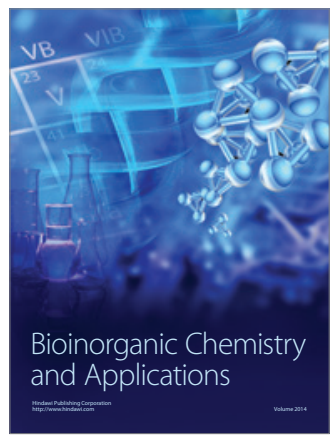

Inorganic Chemistry
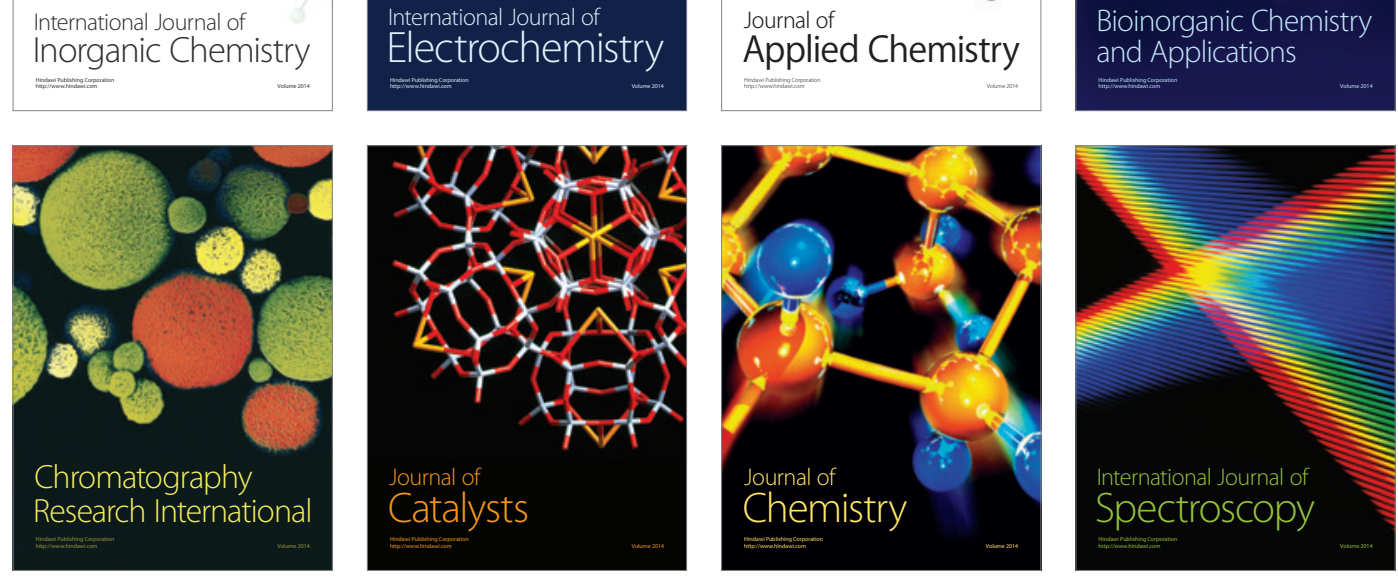